\title{
Sympathetic glial cells and macrophages develop different responses to Trypanosoma cruzi infection or lipopolysaccharide stimulation
}

\author{
Camila Megale de Almeida-Leite ${ }^{1 /+}$, Isabel Cristina Costa Silva ${ }^{2}$, \\ Lúcia Maria da Cunha Galvão3 ${ }^{3}$ Rosa Maria Esteves Arantes ${ }^{2}$ \\ ${ }^{1}$ Departamento de Morfologia ${ }^{2}$ Departamento de Patologia Geral, Instituto de Ciências Biológicas, Universidade Federal de Minas Gerais, \\ Belo Horizonte, MG, Brasil 'Programas de Pós-Graduação em Ciências da Saúde e Ciências Farmacêuticas, \\ Universidade Federal do Rio Grande do Norte, Natal, RN, Brasil
}

Nitric oxide (NO) participates in neuronal lesions in the digestive form of Chagas disease and the proximity of parasitised glial cells and neurons in damaged myenteric ganglia is a frequent finding. Glial cells have crucial roles in many neuropathological situations and are potential sources of NO. Here, we investigate peripheral glial cell response to Trypanosoma cruzi infection to clarify the role of these cells in the neuronal lesion pathogenesis of Chagas disease. We used primary glial cell cultures from superior cervical ganglion to investigate cell activation and NO production after T. cruzi infection or lipopolysaccharide (LPS) exposure in comparison to peritoneal macrophages. T. cruzi infection was greater in glial cells, despite similar levels of NO production in both cell types. Glial cells responded similarly to T. cruzi and LPS, but were less responsive to LPS than macrophages were. Our observations contribute to the understanding of Chagas disease pathogenesis, as based on the high susceptibility of autonomic glial cells to T. cruzi infection with subsequent NO production. Moreover, our findings will facilitate future research into the immune responses and activation mechanisms of peripheral glial cells, which are important for understanding the paradoxical responses of this cell type in neuronal lesions and neuroprotection.

Key words: parasite - nitric oxide - superior cervical ganglion - glial cell culture

The role of sympathetic glial cells in a variety of parasitic diseases remains unknown, despite the clear relevance of their infection and response to parasites to neuronal lesions in autonomic and enteric ganglia. Many studies have elucidated crucial roles for glial cells in neuropathological situations through the release of trophic factors, neuroprotective molecules or neurotoxic chemicals that mediate neuronal survival, function, lesion or death (Garden \& Moller 2006, Giaume et al. 2007). Glial cells are in close contact with neurons in both the central and peripheral nervous systems and are believed to affect them to a greater degree than inflammatory cells and their products (Arantes et al. 2000, Almeida-Leite et al. 2007, Dewil et al. 2007, von Bernhardi 2007). In intestinal Chagas disease, parasitised glial cells and neuronal cells in close proximity to damaged myenteric ganglia is a frequent finding (Tafuri 1970, Arantes et al. 2004). Thus, it is extremely important to elucidate how glial cells are activated by and respond to pathogens, which will help to clarify the mechanisms of pathogenesis for numerous nervous system diseases.

doi: 10.1590/0074-0276130492

Financial support: CAPES Scholarship (to CMA-L), FAPEMIG (to CMA-L: PPP/2009, CDS-APQ-00489-09, to RMEA: PPM/2007, PPM-00200-12), PRPq/UFMG (to CMA-L), CNPq Scholarship (to ICCS), CNPq (to RMEA: 571093/2008-6, 473013/2012-6)

+Corresponding author: camila@icb.ufmg.br

Received 9 October 2013

Accepted 16 June 2014
Central glial cells such as astrocytes and microglia have been investigated in vitro and the intracellular pathways activated in response to various stimuli are well established (Jana et al. 2005, Saha \& Pahan 2006). However, despite their important roles, peripheral glial cells have not been equally well investigated (Griffin \& Thompson 2008, Hanani 2010).

In this study, we used a superior cervical ganglion (SCG) glial cell culture that was standardised by our group (Almeida-Leite \& Arantes 2010) to study and compare how peripheral glial cells and peritoneal macrophages respond to two types of stimuli.

The first stimulus was the protozoan Trypanosoma cruzi, which causes Chagas disease, a significant cause of morbidity and mortality that affects 7.7 million people in Latin America and caused more than 10,000 deaths in 2008 (Strasen et al. 2014). Resistance to T. cruzi infection is associated with the capacity of lymphocytes to generate interferon- $\gamma$ (IFN- $\gamma$ ), which activates macrophages to produce nitric oxide (NO), the main effector molecule that controls intracellular T. cruzi multiplication (Gazzinelli et al. 1992, Vespa et al. 1994). NO is also related to tissue damage (Vespa et al. 1994, Chandra et al. 2002), myenteric denervation (Arantes et al. 2004), neuronal death and reduced neurite density in T. cruzi infection (Almeida-Leite et al. 2007).

It has been found that autonomic glial cells are susceptible to infection in human intestines (Tafuri 1970) and their parasitism and responses have been implicated in neuronal death (Tafuri 1970, Tanowitz et al. 1982). However, it is unclear whether these peripheral glial cells produce inducible NO synthase (iNOS)-derived NO and whether they exert an important role in tissue lesions and 
neuronal death, as observed in T. cruzi infection. It has been suggested that glial-derived NO contributes to the neurodegenerative process observed in the spinal cords of $T$. cruzi-infected interleukin (IL)-12p40 knock-out mice (Bombeiro et al. 2009). In addition to the central nervous system (CNS), the enteric nervous system is also compromised in Chagas disease; however, the autonomic glial cell production of NO has not yet been studied.

The second stimulus used in this study was bacterial lipopolysaccharide (LPS), the major component of the outer membrane of Gram-negative bacteria, which induces potent $\mathrm{NO}$ production and immune responses (Stuehr \& Marletta 1985, Ohmori \& Hamilton 2001). Macrophages and resident glial cells in the CNS (astroglia and microglia) express iNOS and produce high levels of NO in response to a wide variety of pro-inflammatory and degenerative stimuli (Saha \& Pahan 2006). Although the responses of these cells to these stimuli have been well characterised in vitro, the intracellular mechanisms involved are not completely understood.

Because glial cells have a crucial role in neuronal lesions and survival (Hansson \& Ronnback 2003) and are able to produce $\mathrm{NO}$ in response to a variety of stimuli, we aimed to investigate how the response of peripheral glial cells to either T. cruzi infection or LPS differed from the response of peritoneal macrophages. Our goal was to establish the importance of peripheral glial cells as a source of NO in Chagas disease while contributing to the study of glial cell biology. Our observations contribute to the understanding of the intestinal form of Chagas disease pathogenesis based on the high susceptibility of autonomic glial cells to $T$. cruzi infection with subsequent NO production, ultimately leading to neuronal lesions.

\section{MATERIALS AND METHODS}

SCG glial cell culture - Pure primary cultures of SCG glial cells were prepared as previously described (Almeida-Leite \& Arantes 2010). Briefly, SCGs were removed from one-four-day-old C57BL/6 wild-type (WT) mice after decapitation and enzymatically dissociated in $1 \times$ trypsin/ethylenediamine tetraacetic acid solution (Sigma Chemical Company, USA). Isolated sympathetic cells at a final concentration of $10^{5}$ cells/well were plated in cell culture plates (96 or 24-well; Sarstedt, Germany) coated with a 1:5 dilution of Matrigel (Becton Dickinson, USA) in sterile distilled water and cultured in $10 \%$ foetal bovine serum (FBS), $100 \mathrm{UI} / \mathrm{mL}$ penicillin (Sigma-Aldrich, USA) and $10,000 \mu \mathrm{g} / \mathrm{mL}$ streptomycin (Sigma-Aldrich) in Dulbecco's Modified Eagle's Medium (DMEM) (Sigma-Aldrich). The cultures were maintained at $37^{\circ} \mathrm{C}$ in a humidified $5 \% \mathrm{CO}_{2}$ incubator for five-eight days before interventions; the culture medium was changed every $48 \mathrm{~h}$.

Peritoneal macrophage culture - Macrophages were harvested from the peritoneal cavity of adult WT mice at three days after the injection of $2 \mathrm{~mL}$ of $3 \%$ (wt/vol) sodium thioglycolate (Sigma Chemical Company), as previously described (Stuehr \& Marletta 1985, Talvani et al. 2002). After centrifugation at $400 \mathrm{~g}$ for $10 \mathrm{~min}$, the pellet was resuspended in the medium and a single hypotonic lysis was performed as described to remove erythrocytes (du Manoir et al. 2002). Another centrifugation was carried out and the cells were resuspended and plated in cell culture plates (96 or 24-well; Sarstedt), coated with a 1:5 dilution of Matrigel (Becton Dickinson) in sterile distilled water and cultured in $10 \% \mathrm{FBS}, 100 \mathrm{UI} / \mathrm{mL}$ penicillin (Sigma-Aldrich) and 10,000 $\mu \mathrm{g} / \mathrm{mL}$ streptomycin (Sigma-Aldrich) in DMEM (Sigma-Aldrich). After $2 \mathrm{~h}$, the cultures were washed to remove the non-adherent cells, leaving a $97 \%$ pure population of adherent macrophages. The cultures were maintained at $37^{\circ} \mathrm{C}$ in a humidified $5 \%$ $\mathrm{CO}_{2}$ incubator for $24 \mathrm{~h}$ before interventions.

Parasite - The T. cruzi Y strain was used for all experiments. Trypomastigote forms were cultured and purified from the monkey kidney epithelial cell line VERO, as previously described (Braga et al. 1993). Parasites were harvested after six days in culture, centrifuged at $150 \mathrm{~g}$ for $10 \mathrm{~min}$ at room temperature (RT), counted in a Neubauer chamber, centrifuged at $450 \mathrm{~g}$ for $10 \mathrm{~min}$ at $4^{\circ} \mathrm{C}$, suspended in $10 \%$ FBS supplemented 199 medium and used to infect cultures.

T. cruzi infection - T. cruzi trypomastigotes were added to cultures at a parasite-to-cell ratio of 5-10:1. The cells were maintained at $37^{\circ} \mathrm{C}$ in a humidified $5 \% \mathrm{CO}_{2}$ incubator for $48 \mathrm{~h}$ in the presence of $200 \mathrm{UI} / \mathrm{mL}$ of recombinant murine IFN- $\gamma$.

LPS addition - Escherichia coli LPS (L-4130; SigmaAldrich) was added to the cultures at a final concentration of $50 \mathrm{ng} / \mathrm{mL}$. The cells were maintained at $37^{\circ} \mathrm{C}$ in a humidified $5 \% \mathrm{CO}_{2}$ incubator for $48 \mathrm{~h}$ in the presence of $200 \mathrm{UI} / \mathrm{mL}$ of recombinant murine IFN- $\gamma$.

Blockade of iNOS activity - To define the role of NO in $T$. cruzi infection in glial cells in comparison to macrophages, the iNOS inhibitor aminoguanidine (AG) (300 $\mu \mathrm{M}, \mathrm{A} 7009$; Sigma-Aldrich) was added to cultures to block iNOS activity.

Assessment of infection - Cultures were fixed in 10\% neutral buffered formalin solution at $48 \mathrm{~h}$ post-intervention (p.i.) and stained with $10 \%$ Giemsa (Doles Reagents, Brazil). The infection rate was determined by counting the intracellular amastigote forms, as previously described (Vespa et al. 1994, Silva et al. 1995).

Immunofluorescence - Cultured fixed cells were washed in phosphate-buffered saline (PBS), permeabilised with $0.25 \%$ Triton X-100 (Roche, Switzerland) in PBS containing $2 \%$ bovine serum albumin (BSA) (Inlab, Brazil) for $10 \mathrm{~min}$ at RT and incubated with 1:40 normal goat serum in PBS containing $0.25 \%$ Triton X-100 and $2 \%$ BSA for 30 min at RT to block non-specific binding sites. The primary antibodies used to characterise macrophages and glial cells were primary rat anti-mouse F4/80 (1:50; Serotec, UK) and Alexa Fluor 488 goat antirat IgG antibodies and primary rabbit anti-glial fibrillary acid protein (GFAP) (1:100; Dako, Denmark) and Alexa Fluor 488 goat anti-rabbit IgG antibodies (1:400; Molecular Probes, USA), respectively. iNOS expression was detected with primary rabbit anti-iNOS (1:100; Chemicon, USA) and Alexa Fluor 546 goat anti-rabbit 
IgG (1:400; Molecular Probes) antibodies. Secondary antibodies alone were used as specificity controls and uniformly resulted in very low background levels of reactivity. Nuclear staining was assessed using the fluorescent probe Hoechst $(0.2 \mu \mathrm{g} / \mathrm{mL}$; Molecular Probes). The cells were examined by microscopy and digital images were acquired for documentation. The fluorescence intensity was measured by the mean grey value of the binary images from two independent experiments performed in triplicate using Image J 1.45s [National Institutes of Health (NIH), USA].

Evaluation of $\mathrm{NO}_{2}^{-}$production - Culture supernatants collected at $48 \mathrm{~h}$ p.i. and stored at $-20^{\circ} \mathrm{C}$ were assayed for their nitrite concentration by mixing $0.1 \mathrm{~mL}$ of culture supernatant with $0.1 \mathrm{~mL}$ of $0.1 \%$ naphthylethylene diamine dihydrochloride and $1 \%$ sulfanilamide plus $2.5 \%$ phosphoric acid, as previously described (Green et al. 1981). The absorbance at $540 \mathrm{~nm}$ was measured after 10 min and the $\mathrm{NO}_{2}{ }^{-}$concentration was determined by reference to a standard curve of $1-200 \mu \mathrm{M} \mathrm{NaNO}_{2}$.

Statistical analysis - The results were expressed as the mean \pm standard error of the mean (parametric data) or as the median (non-parametric data) of at least three independent experiments. Data were analysed for statistical significance using a non-paired $t$ test (parametric data) or a Mann-Whitney $U$ test (non-parametric data). Probability values (p) of 0.05 or less were considered significant. All analyses were carried out using GraphPad InStat software (USA).

Ethics - All animals used in the research were acquired and cared for in accordance with the NIH Guide for the Care and Use of Laboratory Animals guidelines and the principles presented in the Guidelines for the Use of Animals in Neuroscience Research. All animal protocols were approved by the university Ethical Committee in Animal Experimentation.

\section{RESULTS}

The glial cells in all cultures showed a flat and irregular shape, from spindle-like to polygonal and few cytoplasmic processes. Most glial cells were immunopositive for the glial cell marker GFAP (Fig. 1A). The macrophages in culture showed irregular shapes, from round to fusiform, and were immunopositive for the macrophage marker F4/80 (Fig. 1B). Comparatively, the glial cell cytoplasm was larger than the macrophage cytoplasm (Fig. 1A, B).

After $48 \mathrm{~h}$ of $T$. cruzi infection, most glial cells showed intense parasitism and swollen cytoplasm, with numerous intracellular amastigotes (Fig. 1C). Some macrophages were parasitised and a few intracellular amastigotes could be observed in the cytoplasm (Fig. 1D).

To determine the infection rate, parasitised cells in both cultures were counted. A quantitative analysis showed a higher number of infected cells in the glial cell cultures than in the macrophage cultures (Fig. 2A). However, when iNOS activity was blocked by AG, there was a significant decrease in the number of infected glial cells, with a significant increase in infected macrophages (Fig. 2A).
To calculate the degree of cell parasitism per infected cell in both cultures, the number of intracellular amastigotes was counted per infected cell of 100 cells (Fig. 2B). No statistically significant difference was observed when both cell types were compared in the presence of NO. However, cell parasitism decreased in both cell types when iNOS was blocked by AG (Fig. 2B).

The glial cells expressed iNOS and were highly infected with intracellular amastigotes (Fig. 1E). As expected, the T. cruzi-infected macrophages also showed iNOS immunopositivity (Fig. 1F). When both cultures were compared, iNOS cytoplasmic fluorescence was systematically more intense in the macrophages than in the glial cells (Fig. 1E, F). A quantitative analysis of the fluorescence intensity showed that the macrophages expressed higher iNOS immunopositivity than the glial cells (Fig. 2C).

In comparison to the controls, the T. cruzi-infected and IFN- $\gamma$-activated glial cells showed significantly higher levels of NO production at $48 \mathrm{~h}$ p.i. (Fig. 3A). Similarly, treatment with IFN- $\gamma$ and $T$. cruzi infection resulted in significant levels of NO production in comparison to all controls in macrophage cultures. Nonetheless, the macrophages were more responsive to LPS than to T. cruzi in the presence of IFN- $\gamma$ (Fig. 3A, B). There was no significant difference with regard to NO production between the T. cruzi-infected and IFN- $\gamma$-activated glial cell or macrophage cultures.

LPS addition resulted in significantly higher levels of NO production in both the glial cell and macrophage cultures in comparison to the control, LPS or IFN- $\gamma$ alone at $48 \mathrm{~h}$ p.i. (Fig. 3B). However, the macrophages produced greater amounts of NO when compared to the glial cell cultures when both LPS and IFN- $\gamma$ were present. When the T. cruzi-infected and IFN- $\gamma$-activated glial cell cultures were compared to the LPS and IFN- $\gamma$-activated glial cell cultures, there was no difference regarding NO production, regardless of the stimulus (Fig. 3) and the levels of NO production were very similar.

\section{DISCUSSION}

We used a model of primary glial cell culture from the SCG to investigate glial cell activation and iNOS-derived NO production after T. cruzi infection or LPS addition and compared this to peritoneal macrophage cultures under the same conditions. Here, we show that T. cruzi infection was greater in glial cells than in macrophages, despite similar levels of NO production. Glial cells responded similarly to both stimuli, whereas macrophages responded better to LPS than to T. cruzi infection.

Despite the close association of glial cells to neurons in the peripheral ganglia and CNS and their participation in pro and anti-inflammatory responses (Hansson \& Ronnback 2003, Saha \& Pahan 2006), the cellular activation pathways are not well defined for this cell type (Saha \& Pahan 2006, Hanani 2010). Our group has studied SCG neurons (Almeida-Leite et al. 2007) and glial cells (Almeida-Leite \& Arantes 2010) due to their participation in the neuronal degenerative changes induced by T. cruzi. This parasite has a tropism to nervous tissues in intracardiac ganglia (Machado \& Ribeiro 1989) and the intramural myenteric plexus, a site where glia parasitism 

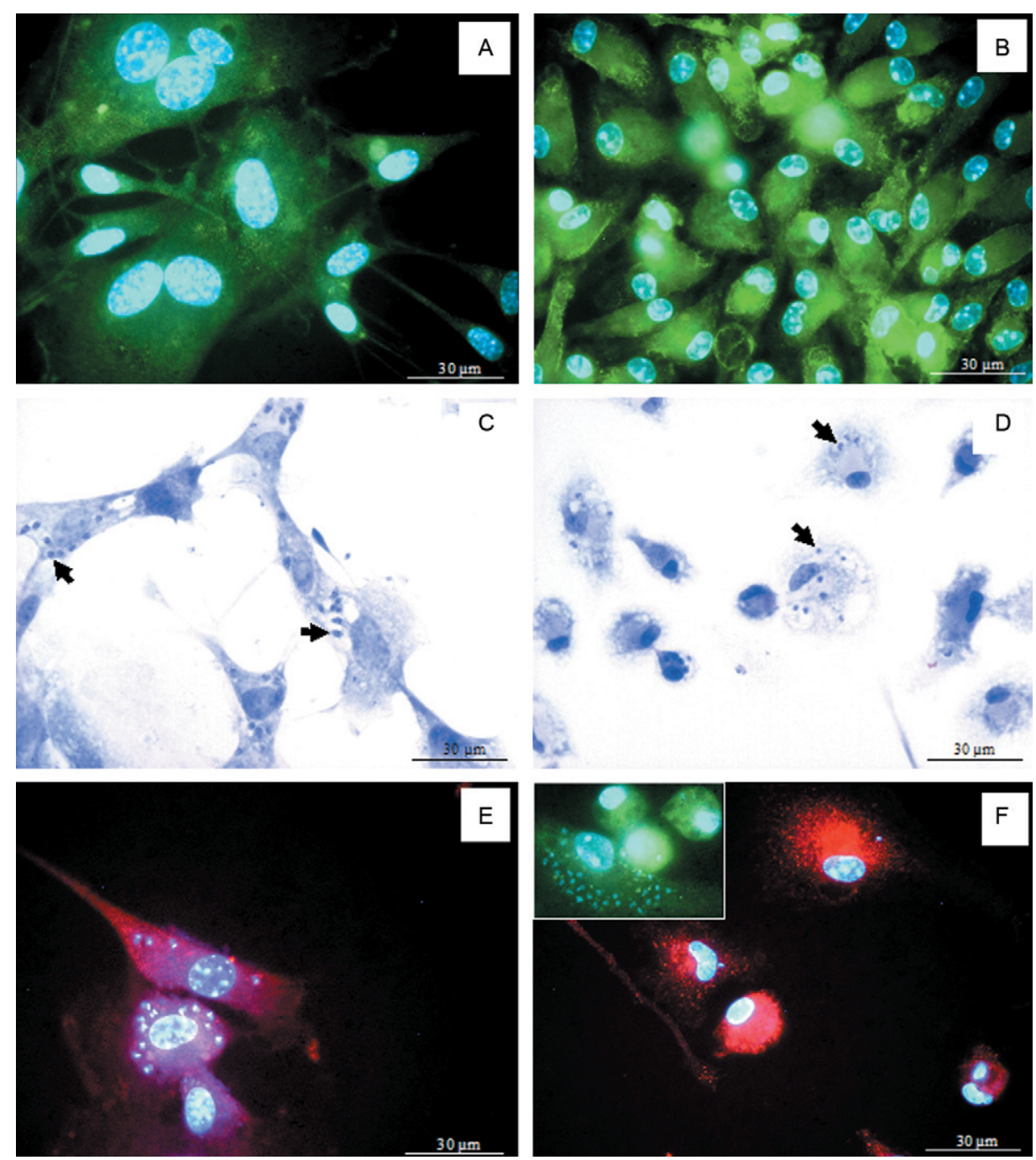

Fig. 1: Trypanosoma cruzi-infected glial cell or macrophage cultures. A, B: glial fibrillary acid protein immunopositive glial cells (A) and F4/80-immunopositive macrophages (B) in culture. Nuclear staining was assessed using the fluorescent probe Hoechst; C, D: T. cruzi-infected glial cells (C) or macrophages (D), showing intracellular amastigotes (arrows) $48 \mathrm{~h}$ post-intervention (p.i.). Giemsa staining; E, F: inducible nitric oxide synthase immunopositivity in T. cruzi-infected glial cells (E) or macrophages (F and insert) 48 h p.i. Nuclear staining was assessed using the fluorescent probe Hoechst.

has been reported, whereas neuronal infection is rarely observed (Tafuri 1970, Arantes et al. 2004). Autonomic ganglia, such as intracardiac and celiac ganglia and the enteric nervous system are preferentially affected in human and experimental Chagas disease and most likely play an important role in the disease's physiopathology (Tafuri 1970, Machado \& Ribeiro 1989, Arantes et al. 2004). The SCG is a prototype of autonomic ganglia and SCG primary neuronal cultures are widely considered a classical instrument of investigation (Blennerhassett et al. 1991). However, SCG glial cells have been less explored than neurons and have never been used for the in vitro study of $T$. cruzi infection.

Our results indicated that in vitro glial cells are susceptible to $T$. cruzi infection, as previously described in vivo (Tafuri 1970, Arantes et al. 2004). Astrocytes are very susceptible to T. cruzi multiplication in vitro (Troyo
\& Chinchilla 2003) and here we show that sympathetic glial cells are susceptible as well, which has implications for neuronal lesions in autonomic and enteric ganglia. Moreover, T. cruzi infection in glial cells was 1.6 times greater than in macrophages at a similar parasite to cell ratio. Despite being infected more easily, glial cells showed no morphological signs of cell degeneration or death. T. cruzi promotes glial cell survival through the neurotrophin-3 receptor TrkC (Weinkauf \& Pereiraperrin 2009, Weinkauf et al. 2011) and it has been shown that macrophages are infected less frequently than are other cell types (Tanowitz et al. 1975), as also observed in our study. It is reasonable to suggest that glial cells have a more permissive behaviour toward T. cruzi infection because they have a larger cytoplasm and are non-professional phagocytes (Pilar \& Landmesser 1976). Furthermore, it has been described that glial cells may favour 

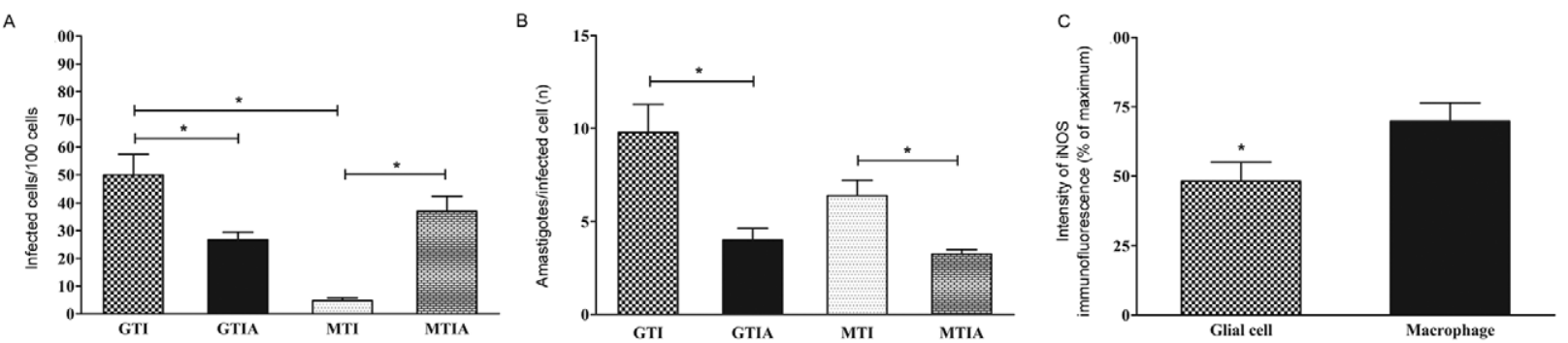

Fig. 2: Trypanosoma cruzi infection and inducible nitric oxide synthase (iNOS) expression in glial cells and macrophages. A: percentage of T. cruziinfected cells in glial cell or macrophage cultures. The data correspond to the mean of five independent experiments \pm standard error of the mean (SEM). Asterisks mean statistically significant difference ( $\mathrm{p}<0.01$, unpaired $t$ test); B: number of amastigotes/cell in $T$. cruzi-infected glial cell or macrophage cultures. The data correspond to the mean of five independent experiments $\pm \operatorname{SEM}(\mathrm{p}<0.05$, unpaired $t$ test); C: intensity of iNOS immunofluorescence in $T$. cruzi-infected glial cell or macrophage cultures $48 \mathrm{~h}$ post-intervention. The data correspond to the mean of two independent experiments in triplicate \pm SEM ( $\mathrm{p}<0.05$, unpaired $t$ test); A: aminoguainidine; G: glial cell; I: interferon- $\gamma$; M: macrophage; T: T. cruzi.
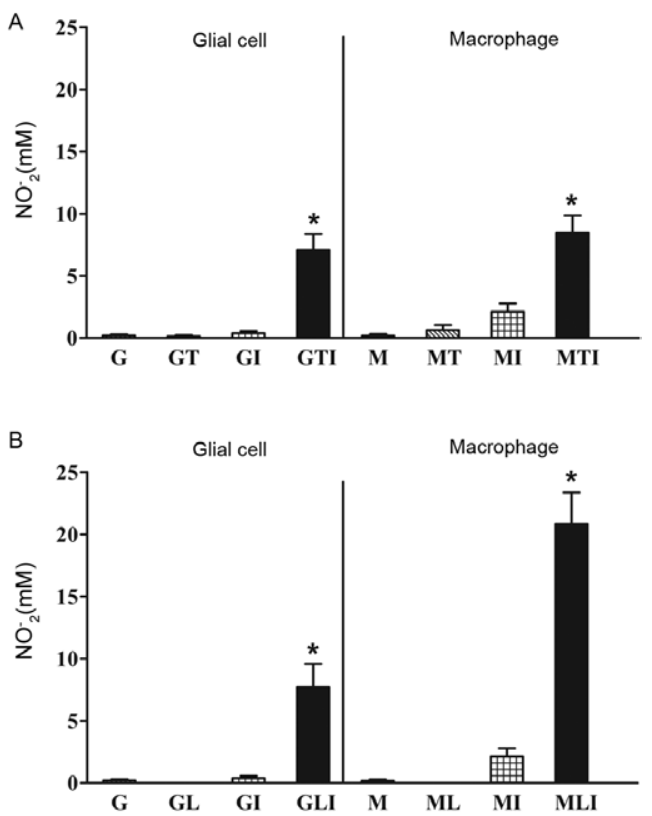

Fig. 3: nitric oxide (NO) production in glial cells and macrophages. Trypanosoma cruzi-infected (A) or lipopolysaccharide-activated glial cell or macrophage cultures (B). The data correspond to the median of four (A) or three (B) independent experiments in triplicate. Asterisks mean statistically significant differences to controls (medium) $(\mathrm{p}<0.01$, Mann-Whitney $U$ test). MLI statistically different from MTI $(\mathrm{p}<0.01$, unpaired $t$ test). G: glial cell; I: interferon- $\gamma$; L: lipopolysaccharide; M: macrophage; T: T. cruzi.

parasite survival and multiplication (Troyo \& Chinchilla 2003). Macrophages, in contrast, are innate immune cells and naturally resistant to intracellular infections (Tanowitz et al. 1975) and may express distinct genes that limit intracellular parasite multiplication (Crocker et al. 1987). T. cruzi invades several cell types by exploiting phagocytic or non-phagocytic mechanisms, depending on the cell involved (Caradonna \& Burleigh 2011). Thus, the entry mechanism of $T$. cruzi into peripheral glial cells deserves further investigation, as has been performed for other cells (Burleigh \& Andrews 1998, Andrade \& Andrews 2004, Weinkauf et al. 2011).
One might predict that the greater infection rate in glial cells would be associated with impaired resistance and deficient NO production. Instead, the supernatant NO levels of $T$. cruzi-infected glial cells were similar to macrophage levels under the same conditions. However, considering that glial cells showed a higher rate of infection and produced similar levels of NO, their response appears to be less intense than that observed for macrophages. When assessing iNOS intensity by immunofluorescence, a lower quantity of expressed protein is observed. The differential regulation mechanisms of the iNOS gene in macrophages and glial cells (Gazzinelli et al. 1992, Vespa et al. 1994, Pahan et al. 1998, Saha \& Pahan 2006) could explain the greater infection rate and similar NO production in glial cell cultures, in agreement with the paradoxical protective role of glial cells.

It has been shown that the parasite Toxoplasma gondii exerts an inhibitory effect on iNOS expression in microglia (Rozenfeld et al. 2005), which may also be the case for $T$. cruzi and SCG glial cells. Moreover, the host defence activity of human microglia against $T$. gondii does not depend on NO, but primarily on IFN- $\gamma$, tumour necrosis factor- $\alpha$ and IL-6 (Chao et al. 1992). The synthesis and secretion of such mediators, as well as leukotriene B4 (Silva et al. 1995, Talvani et al. 2002), could justify distinct infection rates in glial cells and macrophages. It is also known that $T$. cruzi trans-sialidase protects Schwann cells from cell death by activating the phosphatidylinositol 3-kinase/Akt pathway (Chuenkova \& Pereira 2001). Hence, it is possible that our glial cells are more resistant to T. cruzi infection, showing a greater infection rate without morphological evidence of cell death and with less trypanocide activity through NO in comparison to macrophages. However, due to the proximity of glial cells to ganglionic neurons, their products of activation may have damaging effects that may be particularly harmful in both the cardiac and intestinal forms of Chagas disease, as NO has been associated with neuronal death in T. cruzi infection (Almeida-Leite et al. 2007).

Distinct roles for NO in glial cells or macrophages in the control of $T$. cruzi infection might be suggested by the decreased number of infected glial cells when 
iNOS activity was blocked by AG. Although it has been shown that the absence of NO leads to higher parasitism (Arantes et al. 2004), some in vitro studies have demonstrated that the addition of AG decreased cell parasitism, as observed in our study. Other mechanisms known to control parasite replication may also be triggered and the partial inhibition of parasitism was due to cytokine production (Aliberti et al. 1999, Machado et al. 2000). Moreover, both in vivo and in vitro studies have shown that $\mathrm{NO}$ is not required for the control of T. cruzi infection and the enhanced expression of other inflammatory mediators may in part compensate for the lack of iNOS (Cummings \& Tarleton 2004, Marinho et al. 2007). We believe that our glial cells may compensate for iNOS blockade by releasing cytokines and chemokines that control T. cruzi infection to a greater degree than macrophages. We could also assume that NO might be less effective in glial cells as a mechanism of parasite control. In contrast, the blockade of NO production reduced cell parasitism in both cell types and this may be due to distinct mechanisms of parasite uptake and replication, as previously shown (Aliberti et al. 1999).

The addition of LPS induced greater levels of nitrites in macrophage cultures compared to glial cell cultures. Indeed, it is known that T. cruzi and LPS have diverse effects in macrophages by activating different Toll-like receptors (TLRs) (Ropert et al. 2001), whereas glial cell activation pathways have not been well established (Saha \& Pahan 2006). It has been shown that iNOS activation is different in astrocytes and macrophages (Pahan et al. 1998), which led us to believe that peripheral glial cells may also exhibit different levels of iNOS activation. Although macrophages showed greater NO production in LPS-primed cultures in comparison to T. cruzi-infected cultures, glial cells showed similar nitrite levels under either stimulus. Our results indicate that autonomic glial cells respond similarly to LPS and T. cruzi, which are known to activate TLR4 and TLR2, respectively, in macrophages (Hoshino et al. 1999, Ropert et al. 2001). Although the transduction signals generated by distinct TLRs are very similar, cellular responses may be quite different (Campos et al. 2001). Central glial cells respond to LPS via the activation of TLR4 (Lehnardt et al. 2003), as in macrophages (Hoshino et al. 1999); in the presence of LPS, Schwann cells express TLR4 (Cheng et al. 2007) and enteric glial cells produce NO (Cirillo et al. 2011). However, detailed information regarding TRL4 activation following iNOS induction in the presence of LPS in peripheral glial cells has not been described. Thus, it is reasonable to suggest that iNOS activation by $T$. cruzi and LPS in SCG glial cells involves different TLRs. Although is not known whether SCG glial cells express TLR4 or TLR2, this appears likely because they are the best characterised TLRs with regard to the recognition of microbial motifs and LPS, respectively (Hanke \& Kielian 2011). Further studies of TLR expression in SCG glial cells are intended.

Our observations contribute to the understanding of Chagas disease pathogenesis, as based on the high susceptibility of autonomic glial cells to T. cruzi infection with subsequent NO production. Moreover, our findings will facilitate future research into the immune responses and activation mechanisms of peripheral glial cells, which are important for understanding the paradoxical responses of this cell type in neuronal lesions and neuroprotection.

\section{REFERENCES}

Aliberti JC, Machado FS, Souto JT, Campanelli AP, Teixeira MM, Gazzinelli RT, Silva JS 1999. Beta-chemokines enhance parasite uptake and promote nitric oxide dependent microbiostatic activity in murine inflammatory macrophages infected with Trypanosoma cruzi. Infect Immun 67: 4819-4826.

Almeida-Leite CM, Arantes RM 2010. Primary culture of glial cells from mouse sympathetic cervical ganglion: a valuable tool for studying glial cell biology. J Neurosci Meth 194: 81-86.

Almeida-Leite CM, Galvao LM, Afonso LC, Cunha FQ, Arantes RM 2007. Interferon-gamma induced nitric oxide mediates in vitro neuronal damage by Trypanosoma cruzi-infected macrophages. Neurobiol Dis 25: 170-178.

Andrade LO, Andrews NW 2004. Lysosomal fusion is essential for the retention of Trypanosoma cruzi inside host cells. J Exp Med 200: 1135-1143.

Arantes RM, Lourenssen S, Machado CR, Blennerhassett MG 2000. Early damage of sympathetic neurons after co-culture with macrophages: a model of neuronal injury in vitro. Neuroreport 11: $177-181$.

Arantes RM, Marche HH, Bahia MT, Cunha FQ, Rossi MA, Silva JS 2004. Interferon-gamma-induced nitric oxide causes intrinsic intestinal denervation in Trypanosoma cruzi-infected mice. Am J Pathol 164: 1361-1368.

Blennerhassett MG, Tomioka M, Bienenstock J 1991. Formation of contacts between mast cells and sympathetic neurons in vitro. Cell Tissue Res 265: 121-128.

Bombeiro AL, D'Imperio Lima MR, Chadi G, Alvarez JM 2009. Neurodegeneration and increased production of nitrotyrosine, nitric oxide synthase, IFN-gamma and S100beta protein in the spinal cord of IL-12p40-deficient mice infected with Trypanosoma cruzi. Neuroimmunomodulation 17: 67-78.

Braga EM, Galvão LMC, Chiari E, Martins MS 1993. Difference in susceptibility to lysis between clones of the Y strain of Trypanosoma cruzi. Mem Inst Oswaldo Cruz 88: 529-534.

Burleigh BA, Andrews NW 1998. Signaling and host cell invasion by Trypanosoma cruzi. Curr Opin Microbiol 1: 461-465.

Campos MA, Almeida IC, Takeuchi O, Akira S, Valente EP, Procopio DO, Travassos LR, Smith JA, Golenbock DT, Gazzinelli RT 2001. Activation of Toll-like receptor-2 by glycosylphosphatidylinositol anchors from a protozoan parasite. J Immunol 167: 416-423.

Caradonna KL, Burleigh BA 2011. Mechanisms of host cell invasion by Trypanosoma cruzi. Adv Parasitol 76: 33-61.

Chandra M, Tanowitz HB, Petkova SB, Huang H, Weiss LM, Wittner M, Factor SM, Shtutin V, Jelicks LA, Chan J, Shirani J 2002. Significance of inducible nitric oxide synthase in acute myocarditis caused by Trypanosoma cruzi (Tulahuen strain). Int $J$ Parasitol 32: 897-905.

Chao CC, Hu S, Molitor TW, Shaskan EG, Peterson PK 1992. Activated microglia mediate neuronal cell injury via a nitric oxide mechanism. J Immunol 149: 2736-2741.

Cheng C, Qin Y, Shao X, Wang H, Gao Y, Cheng M, Shen A 2007. Induction of TNF-alpha by LPS in Schwann cell is regulated by MAPK activation signals. Cell Mol Neurobiol 27: 909-921.

Chuenkova MV, Pereira MA 2001. The T. cruzi trans-sialidase induces PC12 cell differentiation via MAPK/ERK pathway. Neuroreport 12: 3715-3718. 
Cirillo C, Sarnelli G, Turco F, Mango A, Grosso M, Aprea G, Masone S, Cuomo R 2011. Proinflammatory stimuli activates human-derived enteroglial cells and induces autocrine nitric oxide production. Neurogastroenterol Motil 23: e372-382.

Crocker PR, Davies EV, Blackwell JM 1987. Variable expression of the murine natural resistance gene $L s h$ in different macrophage populations infected in vitro with Leishmania donovani. Parasite Immunol 9: 705-709.

Cummings KL, Tarleton RL 2004. Inducible nitric oxide synthase is not essential for control of Trypanosoma cruzi infection in mice. Infect Immun 72: 4081-4089.

Dewil M, Van Den Bosch L, Robberecht W 2007. Microglia in amyotrophic lateral sclerosis. Acta Neurol Belg 107: 63-70.

du Manoir JM, Albright BN, Stevenson G, Thompson SH, Mitchell GB, Clark ME, Caswell JL 2002. Variability of neutrophil and pulmonary alveolar macrophage function in swine. Vet Immunol Immunopathol 89: 175-186.

Garden GA, Moller T 2006. Microglia biology in health and disease. J Neuroimmune Pharmacol 1: 127-137.

Gazzinelli RT, Oswald IP, Hieny S, James SL, Sher A 1992. The microbicidal activity of interferon-gamma-treated macrophages against Trypanosoma cruzi involves an L-arginine-dependent, nitrogen oxide-mediated mechanism inhabitable by interleukin-10 and transforming growth factor-beta. Eur J Immunol 22: 2501-2506.

Giaume C, Kirchhoff F, Matute C, Reichenbach A, Verkhratsky A 2007. Glia: the fulcrum of brain diseases. Cell Death Differ 14: 1324-1335.

Green LC, Tannenbaum SR, Goldman P 1981. Nitrate synthesis in the germ free and conventional rat. Science 212: 56-58.

Griffin JW, Thompson WJ 2008. Biology and pathology of non-myelinating Schwann cells. Glia 56: 1518-1531.

Hanani M 2010. Satellite glial cells in sympathetic and parasympathetic ganglia: in search of function. Brain Res Rev 64: 304-327.

Hanke ML, Kielian T 2011. Toll-like receptors in health and disease in the brain: mechanisms and therapeutic potential. Clin Sci (Lond) 121: $367-387$.

Hansson E, Ronnback L 2003. Glial neuronal signaling in the central nervous system. Faseb $J$ 17: 341-348.

Hoshino K, Takeuchi O, Kawai T, Sanjo H, Ogawa T, Takeda Y, Takeda K, Akira S 1999. Cutting edge: Toll-like receptor 4 (TLR4)-deficient mice are hyporesponsive to lipopolysaccharide: evidence for TLR4 as the Lps gene product. J Immunol 162: 3749-3752.

Jana M, Anderson JA, Saha RN, Liu X, Pahan K 2005. Regulation of inducible nitric oxide synthase in proinflammatory cytokinestimulated human primary astrocytes. Free Radic Biol Med 38: 655-664.

Lehnardt S, Massillon L, Follett P, Jensen FE, Ratan R, Rosenberg PA, Volpe JJ, Vartanian T 2003. Activation of innate immunity in the CNS triggers neurodegeneration through a Toll-like receptor 4-dependent pathway. Proc Natl Acad Sci USA 100: 8514-8519.

Machado CRS, Ribeiro ALP 1989. Experimental American trypanomiasis in rats: sympathetic denervation, parasitism and inflammatory process. Mem Inst Oswaldo Cruz 84: 549-556.

Machado FS, Martins GA, Aliberti JC, Mestriner FL, Cunha FQ, Silva JS 2000. Trypanosoma cruzi-infected cardiomyocytes produce chemokines and cytokines that trigger potent nitric oxidedependent trypanocidal activity. Circulation 102: 3003-3008.

Marinho CR, Nuñez-Apaza LN, Martins-Santos R, Bastos KR, Bombeiro AL, Bucci DZ, Sardinha LR, Lima MR, Alvarez JM 2007. IFN-gamma, but not nitric oxide or specific IgG, is essential for the in vivo control of low-virulence Sylvio X10/4 Trypanosoma cruzi parasites. Scand J Immunol 66: 297-308.
Ohmori Y, Hamilton TA 2001. Requirement for STAT1 in LPS-induced gene expression in macrophages. J Leukoc Biol 69: 598-604.

Pahan K, Sheikh FG, Namboodiri AM, Singh I 1998. Inhibitors of protein phosphatase 1 and $2 \mathrm{~A}$ differentially regulate the expression of inducible nitric-oxide synthase in rat astrocytes and macrophages. J Biol Chem 273: 12219-12226.

Pilar G, Landmesser L 1976. Ultrastructural differences during embryonic cell death in normal and peripherally deprived ciliary ganglia. J Cell Biol 68: 339-356.

Ropert C, Almeida IC, Closel M, Travassos LR, Ferguson MA, Cohen P, Gazzinelli RT 2001. Requirement of mitogen-activated protein kinases and I kappa B phosphorylation for induction of proinflammatory cytokines synthesis by macrophages indicates functional similarity of receptors triggered by glycosylphosphatidylinositol anchors from parasitic protozoa and bacterial lipopolysaccharide. J Immunol 166: 3423-3431.

Rozenfeld C, Martinez R, Seabra S, Sant'anna C, Goncalves JG, Bozza M, Moura-Neto V, De Souza W 2005. Toxoplasma gondii prevents neuron degeneration by interferon-gamma-activated microglia in a mechanism involving inhibition of inducible nitric oxide synthase and transforming growth factor-betal production by infected microglia. Am J Pathol 167: 1021-1031.

Saha RN, Pahan K 2006. Regulation of inducible nitric oxide synthase gene in glial cells. Antioxid Redox Signal 8: 929-947.

Silva JS, Vespa GN, Cardoso MA, Aliberti JC, Cunha FQ 1995. Tumor necrosis factor alpha mediates resistance to Trypanosoma cruzi infection in mice by inducing nitric oxide production in infected gamma interferon-activated macrophages. Infect Immun 63: 4862-4867.

Strasen J, Williams T, Ertl G, Zoller T, Stich A, Ritter O 2014. Epidemiology of Chagas disease in Europe: many calculations, little knowledge. Clin Res Cardiol 103: 1-10.

Stuehr DJ, Marletta MA 1985. Mammalian nitrate biosynthesis: mouse macrophages produce nitrite and nitrate in response to Escherichia coli lipopolysaccharide. Proc Natl Acad Sci USA 82: 7738-7742.

Tafuri WL 1970. Pathogenesis of lesions of the autonomic nervous system of the mouse in experimental acute Chagas' disease. Light and electron microscope studies. Am J Trop Med Hyg 19: 405-417.

Talvani A, Machado FS, Santana GC, Klein A, Barcelos L, Silva JS, Teixeira MM 2002. Leukotriene B(4) induces nitric oxide synthesis in Trypanosoma cruzi-infected murine macrophages and mediates resistance to infection. Infect Immun 70: 4247-4253.

Tanowitz H, Wittner M, Kress Y, Bloom B 1975. Studies of in vitro infection by Trypanosoma cruzi. I. Ultrastructural studies on the invasion of macrophages and L-cells. Am J Trop Med Hyg 24: 25-33.

Tanowitz HB, Brosnan C, Guastamacchio D, Baron G, Raventos-Suarez C, Bornstein M, Wittner M 1982. Infection of organotypic cultures of spinal cord and dorsal root ganglia with Trypanosoma cruzi. Am J Trop Med Hyg 31: 1090-1097.

Troyo A, Chinchilla M 2003. In vitro multiplication of Toxoplasma gondii and Trypanosoma cruzi in mouse, rat and hamster astrocytes. Rev Biol Trop 51: 639-645.

Vespa GN, Cunha FQ, Silva JS 1994. Nitric oxide is involved in control of Trypanosoma cruzi-induced parasitemia and directly kills the parasite in vitro. Infect Immun 62: 5177-5182.

von Bernhardi R 2007. Glial cell dysregulation: a new perspective on Alzheimer disease. Neurotox Res 12: 215-232.

Weinkauf C, Pereiraperrin M 2009. Trypanosoma cruzi promotes neuronal and glial cell survival through the neurotrophic receptor TrkC. Infect Immun 77: 1368-1375.

Weinkauf C, Salvador R, Pereiraperrin M 2011. Neurotrophin receptor TrkC is an entry receptor for Trypanosoma cruzi in neural, glial and epithelial cells. Infect Immun 79: 4081-4087. 